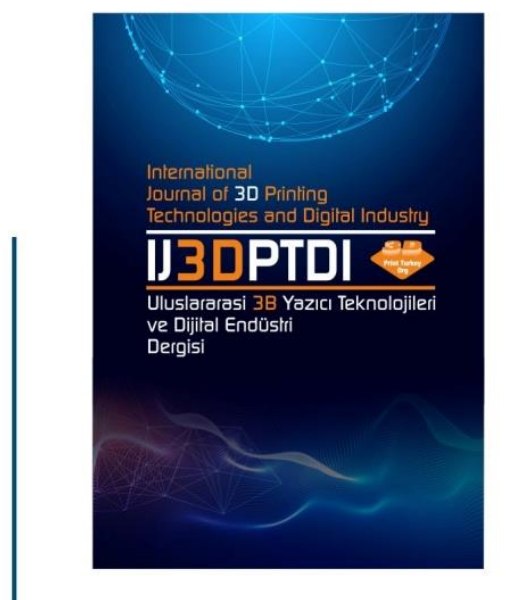

ULUSLARARASI 3B YAZICI TEKNOLOJILERI

VE DIJITAL ENDÜSTRI DERGISI

INTERNATIONAL JOURNAL QF 30 PRINTING TECHNOLOGIES AND DIGITAL INDUSTRY

ISSN:2602-3350 [Online]

URL: https://dergipark.org.tr/ij3dptdi

\title{
A PROPELLER BLADE MANUFACTURING BY HYBRID ADDITIVE MANUFACTURING SYSTEM
}

Yazarlar (Authors): Omer Eyercioglu@, Mehmet Aladag@*

Bu makaleye şu şekilde atıfta bulunabilirsiniz (To cite to this article): Eyercioglu O., Aladag M., "A Propeller Blade Manufacturing By Hybrid Additive Manufacturing System" Int. J. of 3D Printing Tech. Dig. Ind., 5(3): 560-568, (2021). 


\title{
A PROPELLER BLADE MANUFACTURING BY HYBRID ADDITIVE MANUFACTURING SYSTEM
}

\author{
Omer Eyercioglua ${ }^{(\mathbb{D})}$, Mehmet Aladag ${ }^{\mathrm{a}}$ * $*$ \\ ${ }^{a}$ Gaziantep Gaziantep University, Engineering Faculty, Mechanical Engineering Department, Gaziantep, \\ TURKEY. \\ *Corresponding Author: mmehmetaladag@gmail.com
}

(Received: 26.06.2021; Revised: 10.09.2021; Accepted: 30.11.2021)

\begin{abstract}
Hybrid Additive Manufacturing (Hybrid-AM) describes multi-operational or multi-functional additive manufacturing systems. In industry, the increasing tendency in applications of Hybrid-AM brings up the challenge of improving novel methods for the manufacturing of new or hybrid parts. Hybrid AM can produce fully functional assemblies without any assembly operation. In this study, the hybrid additive manufacturing system means that an object is to be designed partly made from prefabricated or off-theshelf parts and added by the wire arc additive manufacturing (WAAM) process. For this purpose, a prototype Hybrid-AM system using the pulsed TIG-Wire-Arc technique was designed and constructed. The constructed The shaped metal deposition (SMD) system has three drivers on the $\mathrm{x}, \mathrm{y}$, and $\mathrm{z}$-axes and an additional rotary driver (fourth axis). Using the Hybrid-AM machine the wire form material can be deposited on an existing primitive profile i.e., a rod, pipe, a profile, or any 3D surfaces with reducing production time. In this way, spiral-shaped features or twisted blade shapes can be added to cylindrical parts. In this study, a stainless- steel propeller blade was deposited on a pipe by using the developed prototype Hybrid AM machine. A non-planar toolpath was used to deposition the subsequent layers and the surface of the propeller blade was finished using 4-axis CNC machining.
\end{abstract}

Keywords: Hybrid additive manufacturing, wire arc additive manufacturing, propeller blade, TIG metal deposition.

\section{INTRODUCTION}

The propellers are the essential parts of the turbine systems of ships and hydro-generators and, they consist of two base parts; hub and blades. Their shapes and structures have significant importance in terms of efficiency. Hub is generally cylindrical geometry and directly connected to the engine or generator shaft in order to transmit the rotational motion. The blades are attached radially to the hub and look like a twisted thick wall slab, however, it has a special geometry that the rotational motion is generated by water flow thanks to its special geometry for hydro-generator. It is the contrast in ships, the rotational motion comes from the engine, then the blade is rotated at a speed; the thrust is also generated thanks to blade geometry. After this basic knowledge, some of the base knowledge might be mentioned about its manufacturing. The blade manufacturing process is long and a difficult period. Almost all manufacturing methods like casting, machining, and polishing are used in a single propeller manufacturing. In particular, blades are manufactured by sand casting, and many operations are required to obtain the final product. As considered the cost and time, a huge amount of expenditures exist. Such that the advantages of the technology always show a way to decrease such loss; additive manufacturing is the best example for the last ten years period. Thanks to its manufacturing principle, the manufacturing of complex parts are obviously eased. Moreover, many process steps were removed in the manufacturing in additive manufacturing.

Additive manufacturing (AM) is an innovative technology with the net or near-net shapes that are used to manufacture solid objects by adding layers of material (filament, wire, or powder) respectively, by melting technique. The melting is obtained by using a focused heat source caused by an electric arc source, electron beam, plasma, or laser beam [1]-[3]. Conventional manufacturing methods are known that have many difficulties in processing certain materials that are including titanium, nickel alloys, etc. Therefore, there is a need for an alternative production technique to compensate for most of these 
difficulties. This production method is a technology that does not require individual tools. Therefore, $\mathrm{AM}$ is an ideal technology for rapid production [4, 5]. Design and manufacturing companies are increasingly adapting to AM to make consumer products, medical and industrial products. In order to reduce time to market, improve product quality and reduce costs, companies that have all scales are trending to $\mathrm{AM}$ as the main tool for rapid product development.

Metal AM methods can be classified according to the energy source that is used (laser, electron beam, etc.), the type of use of the raw material (powder, wire, etc.), or the method of combining the material (such as a laser). Hybrid additive manufacturing makes it possible for the production of fully functional assemblies without any assembly operation. The increasing trend in hybrid additive manufacturing applications has led to the challenge of developing new methods for manufacturing new parts. Generally, there are some basic advantages of using hybrid additive manufacturing in the sector of the AM. AM is the ability to produce outputs directly, which reduces the cost significantly because there is no machining, inventory, assembly, labor, maintenance costs. The AM allows for the production of much more complex geometric shapes, providing greater freedom for new product development. As part size becomes smaller and complexity increases, additive manufacturing is a better option for part production. In AM, if an operator needs a small amount of a product or if the operator is in the prototype stage of the product to be manufactured, it provides the opportunity to easily produce the product without the need for mold making. There is no limit in the design of the product that is wanted to create in AM. Therefore, a designer can produce complex designs that cannot be produced by mold techniques. There are a lot of methods for hybrid additive manufacturing. These hybrid process methods were illustrated in Figure 1.

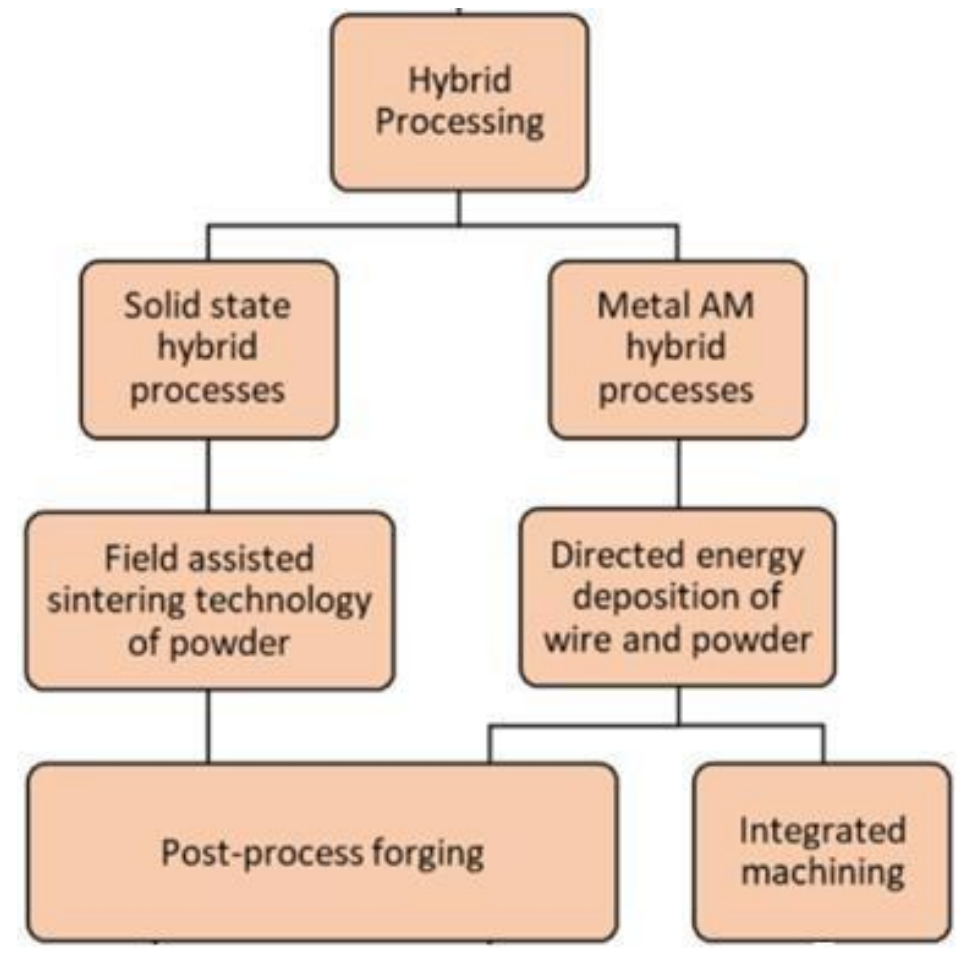

Figure 1. Hybrid process methods.

The shaped metal deposition is one of the methods of hybrid additive manufacturing. Special attention is necessary to obtain the optimum output by SMD. To perform that, the optimum values of wire feed speed, feed rate, and current parameters should be determined during production and products should be manufactured in standard values. These parameters affect the thickness and length of the material that is manufactured and also affect the mechanical properties of the material. The standard values of these parameters were studied and evaluated in the optimization experiments. The SMD is one of the techniques that offer a hopeful approach to satisfy the necessities of the fabrication of net-shaped parts [6]. As a process that is performed without requiring any special tools during the manufacturing is known. This method may be a more useful production technique for components made from expensive 
alloys such as high-grade stainless steel [7-11]. The SMD technology supplies the production of completely dense parts and offers great benefits, especially in the use of any material that can be welded with difficult to machinable and shaped alloys. At the same time, it is clear that the microstructure of the materials produced by the SMD method is more different than materials that are produced by conventional techniques. Because, at the SMD process, the deposited layers expose to high temperatures and rapid cooling. Finally, an anisotropic event can happen in this process [12-14]. The strength and tensile values of the parts that are produced by the SMD technique are slightly higher than those produced by the casting technique $[15,16]$.

Metal is deposited in many melting methods and, the most common one is used in AM is wire arc additive manufacturing. WAAM is a new technique in the production of metal objects with complex surfaces. It first divides the component into layers and makes a path plan according to the shape of the target. Then, with the springs added as the heat source, the metal wires are melted and stacked layer by layer until the component is completely deposited [17]-[19]. Williams et al. created large curved metal components for aerospace using WAAM, including the Ti-6Al-4V, aluminum wing rib models. WAAM enables the realization of the forming of variable cross-section space curved surfaces [20]. However, Ding et al. fabricated a propeller with laser metal-wire additive manufacturing whose blade cross-section is uniform and thin, with dimensions of $80 \mathrm{~mm} \times 80 \mathrm{~mm} \times 120 \mathrm{~mm}$ [21]. For this kind of propeller the infill interior may not be required with a thin blade and equal cross-section, so only need to form a single contour in path planning. In fact, the thickness of the propeller blade is changing, therefore proper toolpath planning must be researched. He et al. studied the high-accuracy and high-performance WAAM propeller manufacture by cylindrical surface slicing method. A propeller was manufactured with the proposed cylindrical surface slicing method. The dimensional errors, therefore, decreased significantly [22] Ya et al. also used WAAM to fabricate a propeller part [23]. A similar study was also made in a master thesis. This study was made on a Hybrid WAAM machine; a TIG welding torch was attached to 4 axes CNC-based machine. By way of the advantage of the 4th axis (rotational axis), hybrid fabrication was enabled. Atalay [24] designed and constructed the hybrid AM machine in such a way that the material can be deposited on an existing object e.g. a rod, pipe, a profile, or any 3D surfaces. This may reduce production time if a primitive profile is used as the substrate. In this way, spiral-shaped features or twisted blade shapes can be added to cylindrical parts. The temperature distribution, and hardness measurements of the printed parts that are produced by this system, were investigated experimentally as the output of his thesis. The aim of this study, a stainless- steel propeller blade was deposited on a pipe by using the developed prototype Hybrid AM machine. A non-planar toolpath was used to deposition the subsequent layers and the surface of the propeller blade was finished using 4-axis CNC machining.

\section{EXPERIMENTAL STUDY}

\subsection{Hybrid-SMD System}

The Hybrid-SMD system was designed and constructed in the Laboratory of Faculty of Mechanical Engineering. The basic devices of the SMD system were revealed in Figure 2. The Hybrid-SMD machine has 4-dimensional linear axes (X, Y, and Z) and a rotational axis (A) which are used for depositing melted wire to manufacture 3D solid components. The electric arc was used by the melting source where the heat source is created between the tungsten electrode and the substrate (workpiece or previous layer). AC/DC, pulsed /non-pulsed current TIG welding is generated by the welding machine which has a capacity of manufacturing. The deposition device unit is a fitting that is used to associate each other the wire feed nozzle and the welding torch such as in Figure 3. 


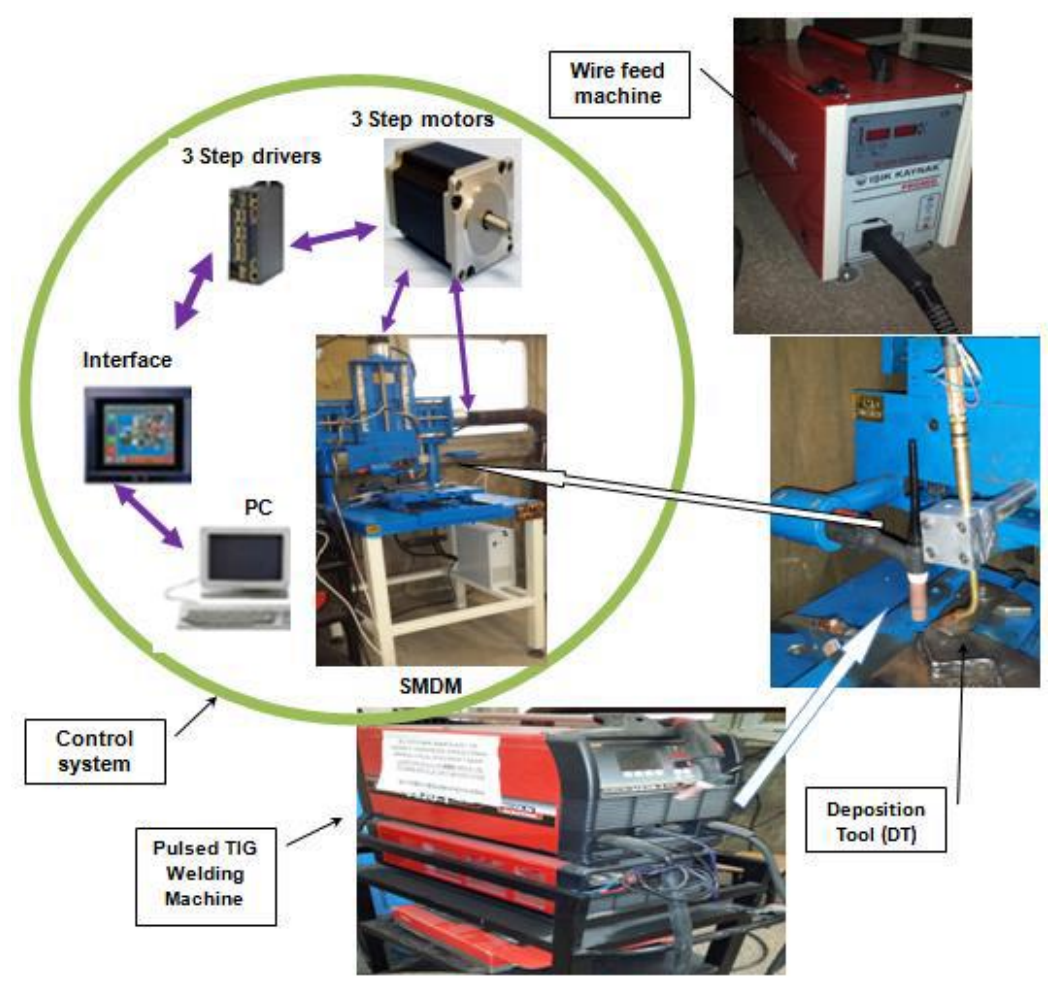

Figure 2. Basic integrated devices in Hybrid-SMD system.

\section{Pulling (backward) Pushing (forward) \\ deposition direction deposition direction}

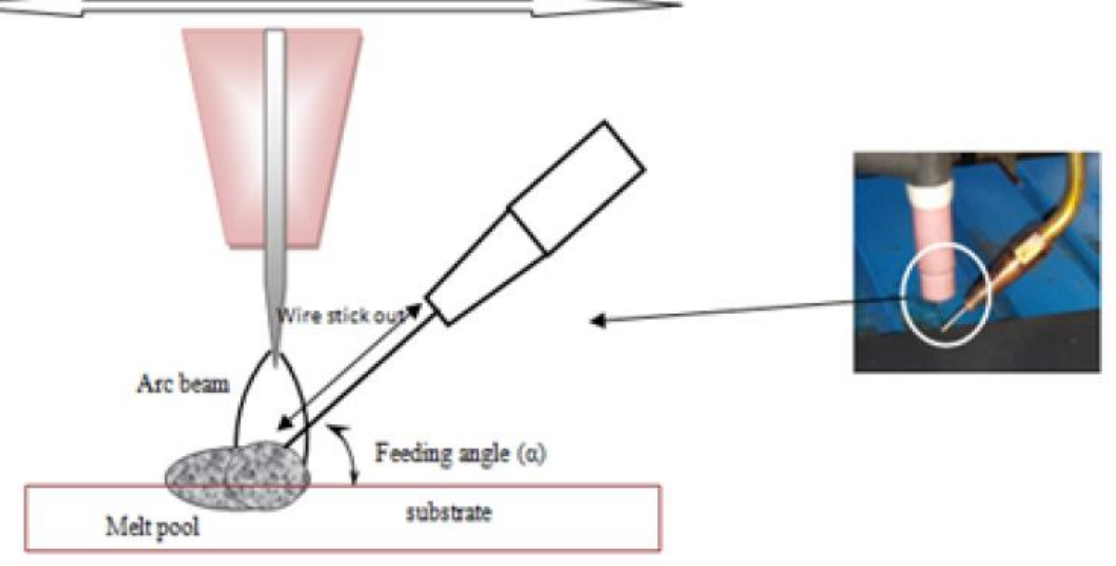

Figure 3. The deposition system

\subsection{Printing Parameters}

Using solid wire material, the process of material deposition was applied by adding a layer on the previous layer in the Hybrid-SMD machine. In this system, there are some parameters that have to adjust at prior to operation. These parameters are travel speed (TS), arc current (I), wire feeding speed (WFS). These parameters are dependent on each other for production. The combination of these parameters is so important for obtaining convenient outputs. On the other hand, the quality of output was affected by conditions that are wire feed direction, shielding gas flow rate, the wire feeding angle, position of wire tip in the welding area. The amount of beads geometry, heat input, and metal deposition rate was controlled by these parameters. In order to adjust the main parameters, a few experiments were done on the Hybrid-SMD machine. Deposited material that is named by 308Lsi, was used to see effects of main parameters at preliminary experiments. 
The travel speed of the welding torch and wire feeding speed was determined by experiments. Wire feeding and travel speed rates concern with the layer's size for the quality of the material. When wire feeding or travel speed rates are changed, automatically part's size will be changed. Accordingly, travel, rotation, and wire feeding speed rates are so important for outputs. Additionally, rotation speed was evaluated in this study due to the Hybrid-SMD machine that could be moved at the rotation axis (A). Therefore, experiments were made on the machine for suitable rotation speed. Wire feeding rate and travel (axial) speed determine the size of the layer. At the same time, these parameters have importance for a near-net-shaped specimen. If they have not appropriate speeds during the process, the layer cannot be produced correctly. Consequently, Hybrid-SMD machine parameters that are determined by experiments were given in Table 1.

Table 1. Nominal process parameters

\begin{tabular}{lcc}
\hline \hline \multicolumn{1}{c}{ Pominal process parameters } \\
\hline \hline Shielding Gas & Values & Units \\
Flow rate & Welding grade Argon & - \\
Pre-flow duration & 12.0 & $1 / \mathrm{min}$ \\
Post flow duration & 3.0 & $\mathrm{sec}$ \\
Arc length & 15.0 & $\mathrm{sec}$ \\
Electrode diameter & 5.0 & $\mathrm{~mm}$ \\
Feeding angle $(\alpha)$ & 3.2 & $\mathrm{~mm}$ \\
Current & 42.0 & Degree \\
Wire Feeding Speed & 60.0 & $\mathrm{~A}$ \\
Travel Speed & 1.7 & $\mathrm{~m} / \mathrm{min}$ \\
\hline \hline
\end{tabular}

\section{RESULT AND DISCUSSIONS}

Hybrid components were produced by the Hybrid-SMD machine. The as-deposited propeller is shown in Figure 4. After the production of the propellers, it was subjected to a post-processing process. In this process, the finished surface was obtained by the milling method, which is the machining method. At the same time, the finish machined propeller blade was presented in Figure 5.

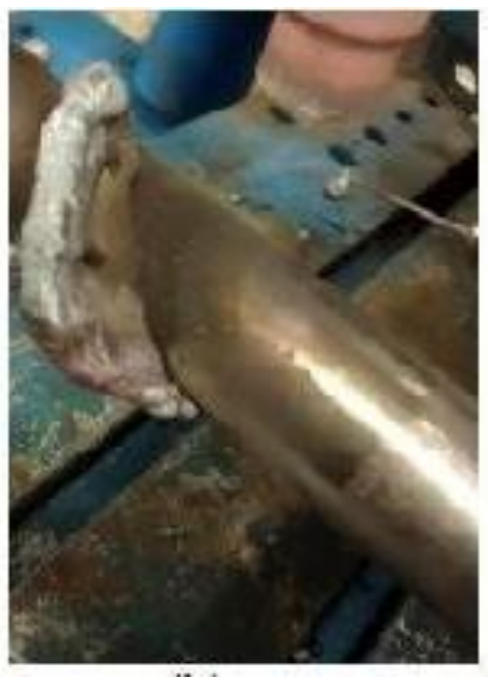

Figure 4. The propeller blade as-deposited by WAAM. 


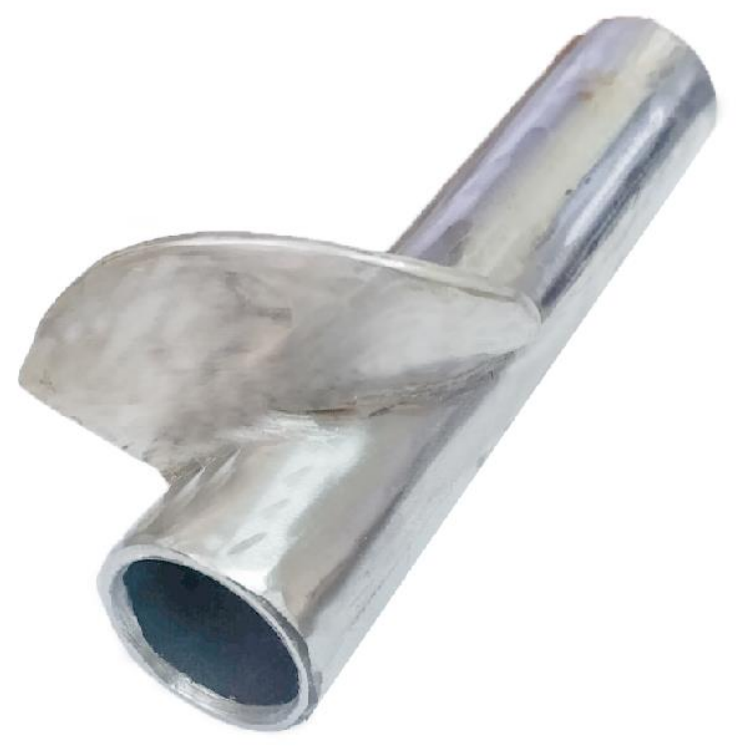

Figure 5. Propeller blade after machining.

Table 2 and Figure 6 show the result of dimensional measurements of layers. At these measurements, the height of layers decreases for each next layer. The height that was calculated according to the theoretical calculation must be $48 \mathrm{~mm}$ (see Figure 6). However, the height that was obtained by the experimental study was measured as $32.2 \mathrm{~mm}$. At the same time, while the width of material should remain constant, each layer eventually showed a continuous increase (see Table 2). The reason for this is that with the increase in temperature, the melting metal spreads due to the weight. In this case, the layer width increases, and the height decreases. These measurements were taken for all 12 layers that were deposited over each other.

Table 2. Variation of height and width of deposition with respect to layers

\begin{tabular}{ccc}
\hline \hline Layer & Height $(\mathbf{m m})$ & Width $(\mathbf{m m})$ \\
\hline \hline 1 & & 7,40 \\
2 & 7,00 & 7,90 \\
3 & 10,80 & 8,20 \\
4 & 14,00 & 8,50 \\
5 & 17,00 & 8,70 \\
6 & 19,80 & 9,00 \\
7 & 22,40 & 9,30 \\
8 & 24,60 & 9,60 \\
9 & 26,80 & 9,90 \\
10 & 28,80 & 10,30 \\
11 & 30,70 & 10,60 \\
12 & 32,20 & 11,00 \\
\hline \hline
\end{tabular}




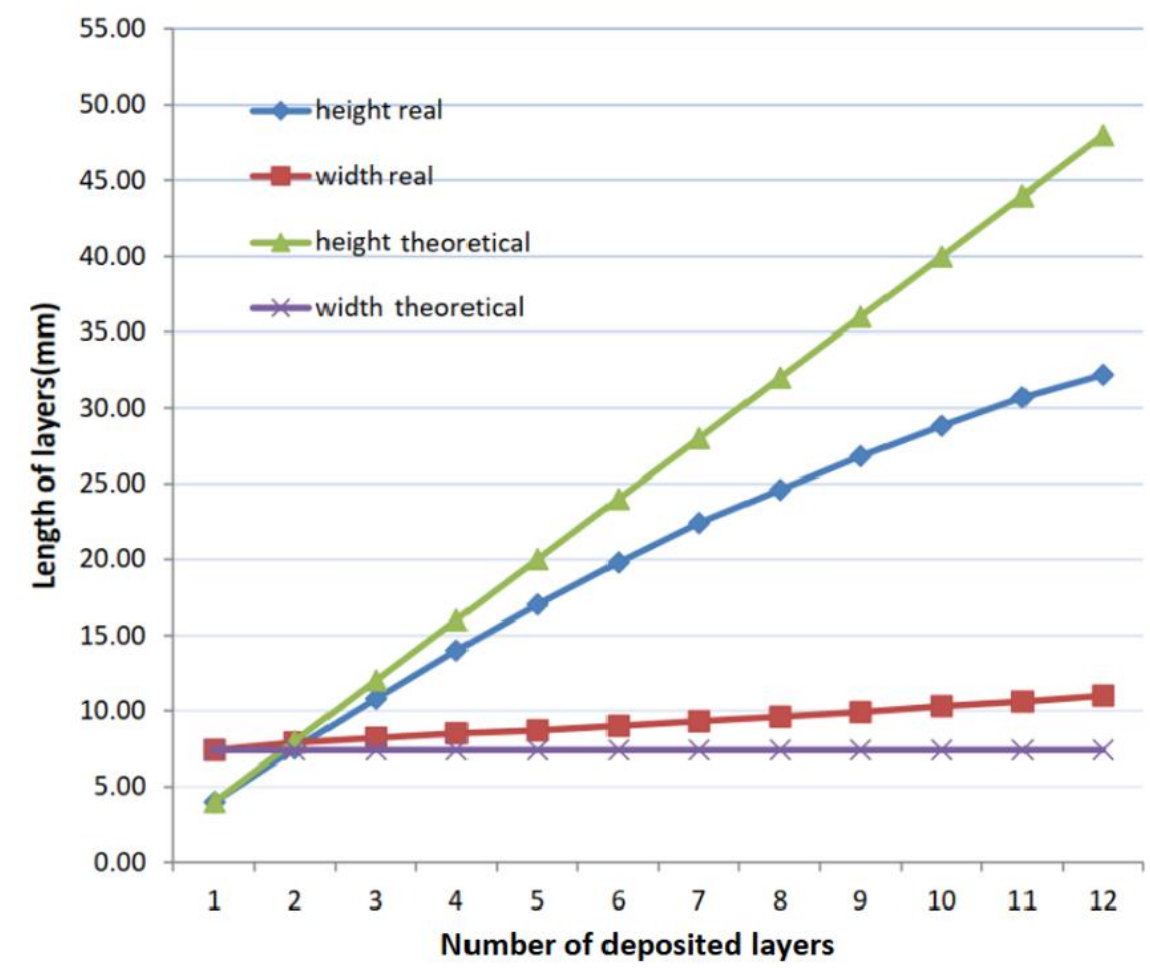

Figure 6. Theoretical and experimental dimensions of the layers
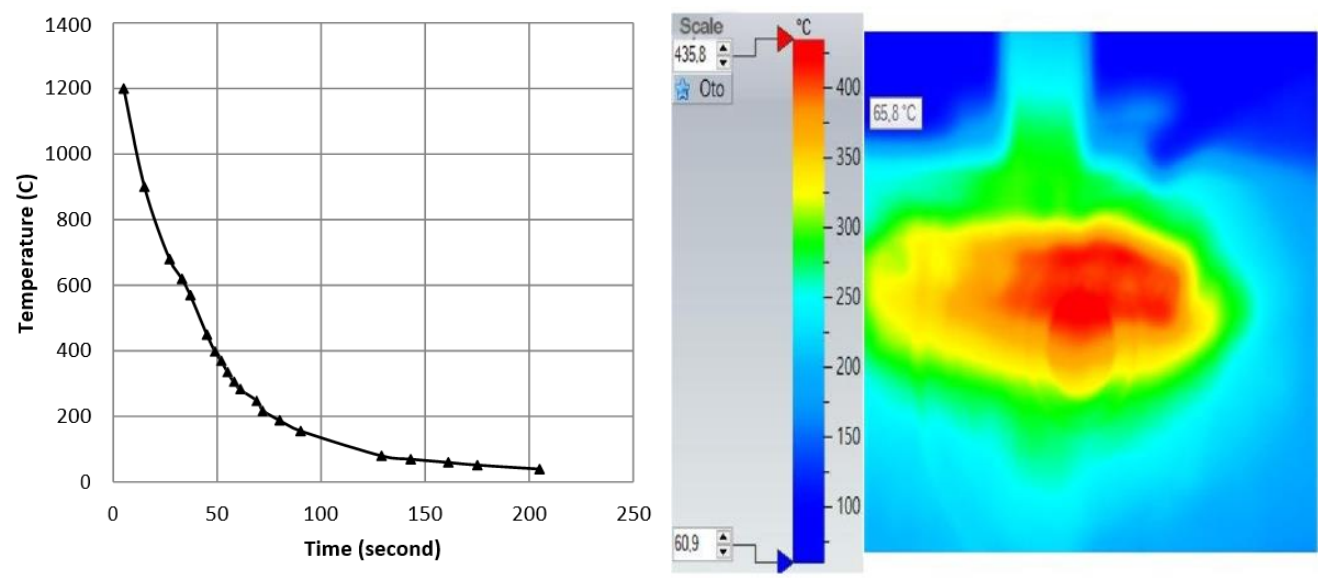

Figure 7. (a) Cooling curve of the first deposited layer (b) Thermal image after deposition of second layer

The relation between the temperature and time of the midpoint of the first layer is illustrated in Figure 7a. The temperature measurements were taken at the end of each layer that is produced by the HybridSMD machine. The thermal image after deposition of the second layer was given in Figure 7b. The thermal camera images for the further layers were given in Figure 8. As it can be seen, when a new layer is put on, the temperature of all layers was affected. Therefore, after the deposition of an additional layer, the cooling time for the subsequent layer was increased progressively. 

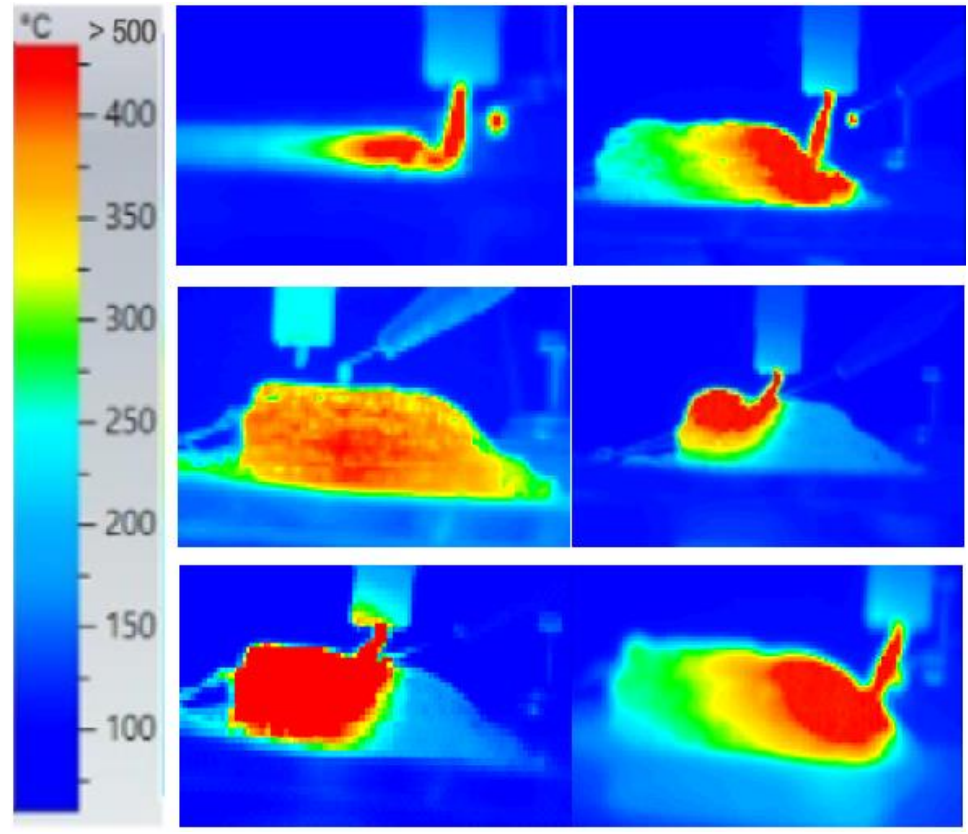

Figure 8. The thermal camera images that was taken during deposition.

\section{CONCLUSION}

In this study, a Hybrid Shape Metal Deposition Machine (Hybrid-SMD) was designed and constructed. The Hybrid-SMD machine can be used to produce hybrid components which have different sizes and metallic materials (wire). Consequently, this study reveals that SMD is an alternative manufacturing process in different industries. The major results of the study can be concluded as follows:

- The designed and constructed machine has 4-axes capability and a controllable wire feeding unit.

- Hybrid-WAAM describes multi-operational or multi-functional additive manufacturing systems. In this study, the AM machine was designed and constructed in such a way that the material can be deposited on an existing object e.g., a rod, pipe, a profile, or any 3D surfaces. This may reduce production time if a primitive profile is used as the substrate. In this way, propeller shapes can be added to cylindrical parts.

- Process parameters (current of welding, travel speed, and wire feeding speed) has to be determined with respect to the required final thickness and height of the deposition.

- It is seen that the complex shape of propellers can be fabricated by Hybrid-WAAM. Therefore, the limitation problems sourced by manufacturability in traditional methods were decreased significantly.

\section{ACKNOWLEDGEMENTS}

The authors would like to acknowledge the contributions of the Scientific Project Bureau (BAPYB) of The Gaziantep University

\section{REFERENCES}

1. Antonysamy A.A., "Microstructure, Texture and Mechanical Property Evolution during Additive Manufacturing of Ti6Al4V Alloy for Aerospace Applications", [Thesis]. Manchester, UK: The University of Manchester; 2012., 2012.

2. Buckner M.A., Love L.J., "Automating and accelerating the additive manufacturing design process with multi-objective constrained evolutionary optimization and HPC/cloud computing", in FIIW 2012 - 2012 Future of Instrumentation International Workshop Proceedings, Pages 51-54, 2012.

3. Gebhardt A., Understanding Additive Manufacturing. Carl Hanser Verlag GmbH, 2011.

4. Mahamood R., Akinlabi E., Shukla M., Pityana S., "Laser metal deposition of Ti6Al4V: A study on the effect of laser power on microstructure and microhardness", 2013.

5. Klahn C., Leutenecker B., Meboldt M., "Design for additive manufacturing - Supporting the substitution of 
components in series products", in Procedia CIRP, Vol. 21, Pages 138-143, 2014.

6. Wang H., Kovacevic R., "Rapid prototyping based on variable polarity gas tungsten arc welding for a 5356 aluminium alloy", Proceedings of the Institution of Mechanical Engineers, Part B: Journal of Engineering Manufacture, Vol. 215, Issue 11, 2001.

7. Mehnen J., Ding J., Lockett H., Kazanas P., "Design forwire and arc additive layermanufacture", in Global Product Development - Proceedings of the 20th CIRP Design Conference, Pages 721-727, 2011.

8. Bonaccorso F., Cantelli L., Muscato G., "An arc welding robot control for a shaped metal deposition plant: Modular software interface and sensors", IEEE Transactions on Industrial Electronics, Vol. 58, Issue 8, 2011.

9. Muscato G., Spampinato G., Cantelli L., "A closed loop welding controller for a rapid manufacturing process", in 2008 IEEE International Conference on Emerging Technologies and Factory Automation, Pages 1080-1083, 2008.

10. Merz R., Ramaswami, Terk K., Weiss M., "Shape Deposition Manufacturing", The Solid Freeform Fabrication Symposium, 1994.

11. Skiba T., Baufeld B., Van Der Biest O., "Microstructure and mechanical properties of stainless steel component manufactured by shaped metal deposition", ISIJ International, Vol. 49, Issue 10, 2009.

12. Baufeld B., Van Der Biest O., "Mechanical properties of Ti-6Al-4V specimens produced by shaped metal deposition", Science and Technology of Advanced Materials, Vol. 10, Issue 1, 2009.

13. Baufeld B., Biest O. van der, Gault R., Ridgway K., "Manufacturing Ti-6Al-4V Components by Shaped Metal Deposition: Microstructure and Mechanical Properties", IOP Conference Series: Materials Science and Engineering, Vol. 26, Issue 1, 2011.

14. Baufeld B., Biest O. Van der, Gault R., "Additive manufacturing of Ti-6Al-4V components by shaped metal deposition: Microstructure and mechanical properties", Materials and Design, Vol. 31, Issue SUPPL. 1, 2010.

15. Clark D., Bache M.R., Whittaker M.T., "Shaped metal deposition of a nickel alloy for aero engine applications", Journal of Materials Processing Technology, Vol. 203, Issue 1-3, 2008.

16. Baufeld B., "Mechanical properties of INCONEL 718 parts manufactured by shaped metal deposition (SMD)", Journal of Materials Engineering and Performance, Vol. 21, Issue 7, 2012.

17. Geng H., Xiong J., Huang D., Lin X., Li J., "A prediction model of layer geometrical size in wire and arc additive manufacture using response surface methodology", International Journal of Advanced Manufacturing Technology, Vol. 93, Issue 1-4, 2017.

18. Li F., Chen S., Shi J., Zhao Y., "In-process control of distortion in wire and arc additive manufacturing based on a flexible multi-point support fixture", Science and Technology of Welding and Joining, Vol. 24, Issue 1, 2019.

19. Panchagnula J.S., Simhambhatla S., "Manufacture of complex thin-walled metallic objects using welddeposition based additive manufacturing", Robotics and Computer-Integrated Manufacturing, Vol. 49, 2018.

20. Williams S.W., Martina F., Addison A.C., Ding J., Pardal G., Colegrove P., "Wire + Arc additive manufacturing", Materials Science and Technology (United Kingdom), Vol. 32, Issue 7, 2016.

21. Ding Y., Akbari M., Kovacevic R., "Process planning for laser wire-feed metal additive manufacturing system", International Journal of Advanced Manufacturing Technology, Vol. 95, Issue 1-4, 2018.

22. He T., Yu S., Shi Y., Dai Y., "High-accuracy and high-performance WAAM propeller manufacture by cylindrical surface slicing method", International Journal of Advanced Manufacturing Technology, Vol. 105, Issue 11, 2019.

23. Ya W., Hamilton K., "On-Demand Spare Parts for the Marine Industry with Directed Energy Deposition: Propeller Use Case", in Industrializing Additive Manufacturing - Proceedings of Additive Manufacturing in Products and Applications - AMPA2017, Springer International Publishing, Pages 70-81, 2018.

24. Atalay Y., "Hybrid Additive Manufacturing by Shaped Metal Deposition", Gaziantep University, 2020. 